The University of Maine

DigitalCommons@UMaine

Publications

Senator George J. Mitchell Center for Sustainability

Solutions

$9-2013$

\title{
Acceptance and Support of the Australian Carbon Policy
}

Stacia J. Dreyer

University of Maine

Iain Walker

Commonwealth Scientific and Industrial Research Organisation

Follow this and additional works at: https:/ / digitalcommons.library.umaine.edu/ mitchellcenter_pubs

Part of the Human Ecology Commons

\section{Repository Citation}

Dreyer, Stacia J. and Walker, Iain, "Acceptance and Support of the Australian Carbon Policy" (2013). Publications. 109. https://digitalcommons.library.umaine.edu/mitchellcenter_pubs/109

This Article is brought to you for free and open access by DigitalCommons@UMaine. It has been accepted for inclusion in Publications by an authorized administrator of DigitalCommons@UMaine. For more information, please contact um.library.technical.services@maine.edu. 
Acceptance and Support of the Australian Carbon Policy

Stacia J. Dreyer, Iain Walker

S. J. Dreyer

School of Economics, University of Maine, Orono, ME, USA

e-mail: stacia.dreyer@maine.edu

S. J. Dreyer, I. Walker

Social and Economic Sciences, Commonwealth Scientific and Industrial Research Organisation

(CSIRO), Floreat, WA, Australia 


\section{Abstract}

In July 2012, the Australian government instituted the Clean Energy Legislative Package. This policy, commonly known as the carbon policy or carbon tax, holds industries responsible for emissions they release through a carbon price. Because this will have an indirect effect on consumer costs, the policy also includes a compensation package for households indirectly impacted. This study, building upon past work in distributive justice, examines the determinants of the policy's acceptance and support. We proposed perceived fairness and effectiveness of the policy, and endorsement of free-market ideology, would directly predict policy acceptance. We tested this through an on-line survey of Australian citizens and found that policy acceptance was predicted by perceived fairness and effectiveness. More Australians found the policy acceptable (43\%) than unacceptable (36\%), and many found it neither acceptable nor unacceptable (21\%).

In contrast, when asked about support, more Australians tended not to support the policy (53\%) than support it $(47 \%)$. Support was predicted by main effects for perceived fairness, effectiveness, free-market ideology, and the interaction between free-market ideology and effectiveness. We conclude by considering some of the implications of our results for the implementation of policies addressing climate change mitigation and adaptation, for theories of social justice and attitudinal ambivalence, and for the continuing integration of research between economics and psychology. Furthermore, we argue for the distinction between policy support and acceptance and discourage the interchangeable use of these terms.

\section{Keywords}


Social justice, Distributive justice, Carbon policy, Policy acceptance, Policy support, Effectiveness, Fairness 
The recent introduction of the Australian carbon pricing policy in July 2012 offers research opportunities concerning the acceptance and support of this policy by Australians. This national environmental policy directly impacts Australia's top polluters, as they are now required to pay a price for their carbon emissions. However, it also has indirect impacts upon Australian citizens in the form of possible higher prices for certain goods produced by those companies. Due to these indirect impacts, this policy also includes financial compensation in the form of a tax credit to offset these costs for many households.

It is important to establish the determinants of this policy's acceptance and support, as emissions will continue rising without national policy and action to curb them. Support and acceptance of carbon policies are a type of environmentally significant behavior (ESB), as these policies affect the behavior of many people and/or organizations at once (Stern, 2000). Defining what makes a carbon policy acceptable to individuals, as well as what makes an individual likely to support a policy, deserves attention because it can help government officials and policy makers craft and maintain policies that have national favor as well as important environmental and socioeconomic benefits.

This study investigates the acceptance of the carbon pricing policy in relation to its perceived fairness and effectiveness, and whether acceptance is related to an individual's subscription to free-market ideology. While much of the environmental policy literature assesses a hypothetical policy or one that may be enacted in due time, this study is unique in its investigation of the recently enacted Australian carbon policy. Furthermore, although much of the literature does not 
differentiate between the terms "acceptance" or "support" this research investigates whether the ideas of policy acceptance and policy support are interchangeable or discrete concepts.

\section{Acceptability, Acceptance, and Support}

Acceptance of a policy differs from acceptability of a policy mainly in regards to timing. Acceptability is a favorable or unfavorable evaluation of a policy before implementation, whereas acceptance is the evaluation after implementation (Schuitema, Steg, \& Forward, 2010). ${ }^{1}$ This evaluation can also be thought of as a positive or negative attitude toward the policy, and thus is an attitude construct (Schade \& Schlag, 2003). Schade and Schlag (2003) argue that acceptance includes a behavioral reaction, whereas acceptability refers solely to attitudes. They note that acceptance has been used to describe many constructs, such as "support, agreement, feasibility, to vote for, favorable reaction” depending upon the study (p. 47).

Overall, support and acceptance have not been operationally defined in regards to environme ntal policies. When speaking about favorable or unfavorable evaluation/attitudes of an environmental policy, some researchers prefer the term "support" and use it consistently throughout their writing (Dietz, Dan, \& Shwom, 2007; Leiserowitz, Maibach, Roser-Renouf, \& Hmielowski, 2012), while others use the term "acceptance" or "acceptability" interchangeably with support (Gross, 2007; Schuitema et al., 2010; Steg, Dreijerink, \& Abrahamse, 2005, Steg, Dreijerink, \& Abrahamse, 2006; Swim et al., 2011; Wegener \& Kelly, 2008). 
Stern, Dietz, Abel, Guagnano, and Kalof (1999) identify and describe three dimensions of support for environmentalism: citizen action, policy support and acceptance, and personal sphere behavior. However, within the second dimension, policy support and acceptance, a description of the similarities and differences between policy support, and policy acceptance is not offered.

Wüstenhagen, Wolsink, and Bürer (2007) define the social acceptance of renewable energy innovation, but do not distinguish social acceptance from support. They conceptualize social acceptance as having three core components: socio-political, community, and market acceptance. Socio-political acceptance is the most general type and thus concerns the acceptance by the public, key stakeholders, and/or policy makers. Community acceptance is more localized and can be examined in light of trust, distributive justice, and procedural justice. Market acceptance is based around support from consumers, investors, and firms. Separating these three aspects of social acceptance can help explain why an individual might view sustainable technologies or energy policies as acceptable, in general, but not take favorably to the building of such an energy site in their community (Wüstenhagen et al., 2007).

Climate change is both a general and localized issue, and thus it could be argued that community acceptance must be merged with socio-political acceptance for policies relating to climate change. The carbon pricing policy instituted in Australia affects all Australians, but not everyone is compensated similarly, nor are industries held accountable similarly. Therefore, this project combines these two ideas of acceptance into an overall acceptance model while also assessing 
the perceived fairness and effectiveness of the policy. As we do not incorporate all three aspects of social acceptance into our project, we will use the term acceptance instead of social acceptance.

\section{Social Justice and Climate Change}

Environmental researchers have argued that social justice concepts, such as distributive and procedural justice, must be considered when creating environmental policies (Bubna-Litic \& Chalifour, 2012; Gross, 2007). In addition, the political feasibility of policy implementation must be considered as well as the need for consistent measurement with quantitative targets to assess effectiveness (Wolkinger et al., 2012). At times, tools used to measure predicted costs and benefits of carbon mitigation, such as carbon abatement curves, fail to accurately capture the impact on those groups who are disproportionally affected by climate change, such as poor communities in rural areas and disadvantaged populations in urban areas like the elderly, children, and those living in poverty (Casillas \& Kammen, 2012). Increased costs due to carbon pricing have unequal effects upon those individuals and families with lower incomes in both urban and rural areas, as a higher percent of their weekly expenditures are spent on goods with increased costs. ${ }^{2}$ This is the reason for inclusion of the compensation package in Australian carbon policy. It is important that alongside the perceived and actual effectiveness of a policy, we also study concepts of social justice, as these ideas are inextricably connected. 
This current research draws on past research in energy/climate policy and travel demand management related to social justice to inform our hypotheses regarding the current carbon policy. Perceived effectiveness and perceived fairness have both been linked to the acceptability of a proposed environmental policy, as well as acceptance of an implemented policy (Schuitema et al, 2010; Schuitema, Steg, \& Rothengatter, 2010; Steg, Dreijerink, \& Abrahamse, 2006). Both individual factors and characteristics of the proposed policy are important for predicting acceptability (Steg et al, 2006).

Perceived fairness of policy has been shown to be important for policy acceptance (Skitka, Winquist, \& Hutchinson, 2003; Tyler, 2000; Visschers \& Siegrist, 2012). Two main components of perceived fairness need to be considered when assessing fairness: distributive justice and procedural justice (Bubna-Litic \& Chalifour, 2012; Gross, 2007). Distributive justice refers to outcomes received from the policy and how those compare to the outcomes others receive. Procedural justice refers to the processes that were used to inform the outcomes (Tyler, Boeckmann, Smith, \& Huo, 1997; see Thibaut \& Walker, 1978, for seminal work). Judgments of procedural and distributive justice are conceptually independent. Both the outcome and the process used to achieve that outcome can be perceived as fair, or only one or the other, or neither can be seen as fair. They are, however, normally correlated. Depending upon the situation and the institutional framework of a given country, one component can be more important for decision-making than the other (Tyler et al, 1997). For example, Visschers and Siegrist (2012) found that distributive justice was more important than procedural justice in accepting the decision to rebuild nuclear power plants in Switzerland. On the other hand, people may accept a policy they view unfavorably because the process in which it was developed is viewed as fair 
(Tyler et al.). Within this work, we look specifically at aspects of distributive justice, as we are interested in both the fairness of the compensation package and holding industries responsible for emissions via a carbon price, as opposed to the process of creating the policy (procedural justice).

Perceived effectiveness is also positively related to acceptability, as those who perceive a policy as more effective are also more likely to indicate higher levels of acceptability (Eriksson, Garvill, \& Nordlund, 2008; Gärling \& Schuitema, 2007; Steg et al., 2006). People want to believe that the policy implemented will be effective in solving the issue it sets out to change or protect. If it is not effective in creating change, then why institute it? For a tax/revenue-based policy, acceptance of the policy is also contingent upon the allocation of revenues (Steg et al., 2006). Lastly, acceptability of a policy normally increases after policy implementation (Schuitema et al., 2010), provided that it is perceived as fair and effective overall. These two last elements exist in the carbon pricing policy; the revenues from the carbon price, in part, will be redistributed to individuals as tax compensation and the policy is currently implemented. Thus, for our study, we hypothesized that acceptance would be positively related to perceived fairness and effectiveness.

Studies do not always support the above-mentioned findings; de Groot and Steg (2006) found, for example, that individuals did not have strong opinions regarding the acceptability of a proposed policy to double the prices of car use, nor did they believe a price increase would significantly decrease their quality of life. Furthermore, Gehlert and Neilson (2007) found no difference in the acceptability of a toll charge before and after implementation. However, these 
studies assessed policies related to car use, which are also impacted by personal habit in such a way that a carbon pricing policy does not.

The influence of perceived effectiveness and fairness on acceptance of an environmental policy may not be additive; the effect of fairness on acceptance may also depend upon the level of perceived effectiveness and vice versa. For example, if either perceived fairness or effectiveness is low, then acceptance of the policy may be low. These variables may not be completely independent of one another, but if both are high, then acceptance should be high, and if one or both are low, acceptance should be low. Thus, we also hypothesize an interaction between perceived effectiveness and fairness on acceptance levels.

\section{Free-Market Ideology and Climate Change}

Free-market ideology refers to the belief that markets should be allowed to exist unrestrained by government regulations. According to this view, the market will resolve any problems which occur through supply and demand dynamics (Heath \& Gifford, 2006). An "invisible hand" is the self-regulating control mechanism for the market (Smith, 1904); government need not interfere with regulations or policies because the 'invisible hand' prevents market failure (Jaffe, Newell, \& Stavins, 2005). Accordingly, if the market can take care of itself, then individuals need not concern themselves with the environmental costs of the market. However, the existence of negative externalities or slowed adoption of technology indicates market failure (Jaffe et al., 2005). As the market does not account for negative externalities, such as greenhouse gas 
emissions, an organization has no economic incentive to reduce their emissions. Therefore, policies are created, such as a carbon policy, which create incentives for an industry to minimize the externality. This is executed in two main ways by either imposing a limit, or cap, on the level of pollution, and/or internalizing the environmental costs and allowing the industry to make a decision on their consumption/production of the environmental inputs/outputs (Jaffe et al, 2005).

Subscription to a free-market ideology is associated with both the rejection of climate science (Lewandowsky, Oberauer, \& Gignac, 2013) and a belief that global warming is naturally caused (Heath \& Gifford, 2006). No studies yet investigate if subscribing to a free-market ideology influences support or acceptance of an environmental policy. However, based on past findings regarding the rejection of climate science and belief that global warming is naturally caused, and the fact that a policy serves as a market regulation, we posit a negative relationship between freemarket ideology and policy support or acceptance. Policies that aim to reduce greenhouse gas emissions, and thus climate change, create an ideal situation to study this potential relationship.

The strength of subscription to a free-market ideology may also impact the influence of perceived effectiveness or fairness on policy acceptance. An individual who highly endorses a free-market ideology may not find any environmental policy acceptable, even if certain aspects of the policy are deemed effective or fair. Free-market ideology may act as a moderator of the relationship, only allowing perceived effectiveness and fairness to influence acceptance if freemarket ideology is low. 
In sum, we are interested in how Australians' acceptance of the carbon pricing policy is related to perceived fairness, effectiveness, and free-market ideology. We hypothesized that acceptance would be positively related to perceived fairness and effectiveness and negatively related to an endorsement of free-market ideology. Furthermore, we hypothesized an interaction between perceived effectiveness and fairness on acceptance levels, and hypothesized that this interaction would be moderated by free-market ideology. We made no different hypotheses concerning policy support. While support and acceptance can be differentiated, there were no reasons to predict different relationships given the interchangeable use of the terms in the literature. ${ }^{3}$

\section{Methods}

Participants

In November 2012, we surveyed 616 Australian adults representing metropolitan, regional, and rural areas on-line. The sample included 305 men and 311 women between the ages of 18 and 87. Respondents were drawn from a research-only panel with an incentive to be entered into a prize drawing. ${ }^{4}$ See Table 1 for a comparison of our sample to the Australian population. A target sample of 600 individuals was proposed before the sampling began to adequately ensure enough participants for the analyses, and 12,000 invites were sent out within the panel. Of these invites, 1,084 respondents clicked the link from their personal computers, and 616 completed the survey, resulting in a $57 \%$ completion rate. The survey was closed on the morning our target sample was reached, resulting in a total of nine data collection days. 


\section{Measures}

This study was part of a larger survey assessing Australians' views on the carbon pricing policy, climate change, and other environmental topics. Only sections used within this study will be discussed, see Appendix 1 for these sections.

Section 1: Free-Market Ideology

This first section included Heath and Gifford's (2006) free-market ideology scale. These statements were measured on a 5-point Likert Scale ranging from "Strongly Disagree" to "Strongly Agree" and included statements such as "An economic system based on free-markets unrestrained by government interference automatically works best to meet human needs" and 'The preservation of the free-market system is more important than localized environmental concerns." Responses were recoded so that a higher score aligned with endorsement of a freemarket ideology. One statement was omitted from further analysis from this scale, as supported by the results of a principal factor analysis, and in accordance with Lewandowsky et al. (2013) $(\alpha=.77)$. In addition to the free-market ideology scale, two questions were also included in this section specific to the beliefs about industry responsibility of emissions and compensation, 'Industries should be responsible for paying for the greenhouse gases that they emit, such as carbon," and "Individual consumers should be financially compensated to offset increased costs on goods resulting from a carbon price." All questions in this section appeared in random order. 
Section 2: Policy Acceptance and Support

This section assessed acceptance based on questions created specifically for the carbon policy. To make sure all participants had a basic knowledge of the policy, a brief introductory summary was presented with facts taken from the government-issued website regarding the policy (see Appendix 1). It introduced the Clean Energy Legislative Package and briefly spoke about the carbon price and compensation plan.

The first question asked about overall acceptance of the policy "How acceptable do you find the Clean Energy Legislative Package?" Participants were then asked about the fairness and effectiveness of industries paying for the carbon they emit, and the fairness and effectiveness of individuals receiving compensation due to increased costs resulting from the carbon price. All questions in this section were measured on a 5-point Likert scale, and the terms used were relative to the questions asked (for the fairness question, response categories ranged from "completely unfair" to "completely fair"). The two fairness questions and the two effectiveness questions were then averaged to create an index score $(\alpha=.69$ and $\alpha=.78$, respectively). A dichotomous choice question regarding support of the policy concluded this section, "Do you support the carbon policy (The Clean Energy Legislative Package)?”

Section 3: Demographics 
Standard demographics were assessed in this section.

\section{Results}

Correlations between variables are presented in Table 2, along with descriptive statistics. Means and standard deviations for each dependent variable by level of acceptance and support are presented in Table 3.

During our exploratory analysis, we noticed differences in the number of people who indicated they supported the policy versus found the policy acceptable. Interestingly, we found that more Australians found the policy completely acceptable or somewhat acceptable (42.9\%) than completely unacceptable or unacceptable (35.7\%); $21.4 \%$ found it neither acceptable nor unacceptable. However, in contrast to the acceptance analysis, slightly more Australians did not support the policy (52.9\%) than supported it (47.1\%). The finding that more Australians accept the policy than support it is odd, and conflicts with the interchangeable use of those terms in the literature. Policy acceptance and policy support were positively correlated $(r=.66, p<.01)$. We further analyzed the two questions about support and acceptance separately.

We performed a standard multiple regression with the level of acceptance of the policy as the dependent variable, and a direct logistic regression with support of the policy as the dichotomous dependent variable. Perceived fairness, perceived effectiveness, and subscription to free-market 
ideology were used as predictor variables. Three two-way interactions and one three-way interaction between those variables were also included. Variables were centered at the means to reduce issues of multicollinearity within the interactions (Tabachnick \& Fidell, 2007). Covariates for age, income, and gender were tested, but did not significantly affect the model and therefore were removed from analysis. We controlled for support in our multiple regression and acceptance in our logistic regression so we could analyze the unique effects of each while controlling for the other. Table 4 displays the multiple regression results.

The predictor variables for acceptance accounted for almost two-thirds of the variance in acceptance, $F(8,615)=138.27, p<.001, R^{2}=.65$. Perceived effectiveness and fairness were the only two variables that emerged as significant predictors for acceptance (see Table 4). Individuals who reported higher levels of perceived effectiveness or fairness were more likely to find the policy acceptable than those individuals reporting lower levels.

A test of the full logistic regression model for support, with all eight predictors against a constant-only model, was statistically significant, $\chi^{2}(8)=465.46, p<.001$, indicating that the predictors as a set reliably distinguished between those who supported the policy and those who did not. Prediction success overall was $86.5 \%$, with $89.3 \%$ for "do not support" and $83.4 \%$ for "support."

Regression results are listed in Table 4. According to the Wald criterion, three main effects and one interaction predicted support: perceived fairness, perceived effectiveness, free-market 
ideology, and the interaction between effectiveness and free-market ideology $(p=.052$ for freemarket ideology). $\operatorname{EXP}(B)$ interpretations show that for a one-unit increase in the levels of perceived fairness (somewhat unfair to neutral, or somewhat fair to completely fair) an individual is about two and a half times more likely to support the policy. For a one-unit increase in perceived effectiveness an individual is about three and a half times more likely to support the policy. In contrast, a one-unit increase in subscription to free-market ideology, results in an individual being about one-half times less likely to support the policy.

For the interaction, the stronger one's subscription to a free-market ideology is, the less likely they are to support the policy - except when effectiveness is high. When effectiveness is perceived to be high, those who are high in free-market ideology as well as those low in freemarket ideology are equally likely to support the policy.

In sum, the regression results for support highlight unique predictors for support, relative to acceptance. These are free-market ideology and the interaction between free-market ideology and effectiveness. Both support and acceptance share perceived fairness and perceived effectiveness as significant predictors. Both support and acceptance are positively correlated with perceived fairness and effectiveness and negatively correlated with free-market ideology ( $p s<$ $.05)$.

\section{Acceptance by Support Analysis}


As mentioned above, the data showed unexpected results concerning differences in the level of acceptance and support. We generally expected the same people to find the policy acceptable and to support the policy—or to find the policy unacceptable and not support the policy (with a bit of variance due to our neutral category in acceptance). A large percentage of the sample was "neutral" in their acceptance (21.4\%). We wondered how those neutral participants responded when forced to make a choice on our question regarding support. Due to the different measurement metrics on the two questions, we were able to investigate further.

Policy support was assessed within the neutral acceptance category in which an individual was coded "1" if they were neutral in acceptance and supported the policy and a "0" if they were neutral in acceptance and did not support the policy. All other cases were handled as missing cases.

Of the participants who were neutral on policy acceptance, 44 indicated they supported the policy, and 88 indicated they did not support the policy. These two groups were compared more closely. There were significant differences on effectiveness, fairness, and industry responsibility for the groups. Those who supported the policy thought it was more effective $(M=3.20)$ than those who did not $(M=2.52), t(130)=5.95, p<.001 .{ }^{5}$ Those who supported the policy also thought it was more fair $(M=3.48)$ than those who did not $(M=3.11), t(130)=3.60, p<.001$. Lastly, policy supporters also had a higher belief in industry responsibility $(M=3.80)$ than those who did not $(M=3.53), t(130)=2.14, p<.05$. 


\section{Discussion}

This study aimed to better understand how perceived fairness, effectiveness, and free-market ideology were related to policy acceptance. Important findings arose from this research. First, two predictors of policy support were found to be unique from policy acceptance, which along with the differing levels of support and acceptance, suggest the existence of distinct constructs. Second, we found an interaction between free-market ideology and effectiveness for support. When effectiveness is perceived to be high, all are equally likely to support the policy regardless of their endorsement of a free-market ideology. The importance of the current findings is discussed further below.

Finding different predictors of acceptance versus support of the policy was unexpected. As these terms are used interchangeably within the literature we would expect for them to be measuring the same construct. In making their case for differentiating between acceptability and acceptance, Schade and Schlag (2003) define acceptance as attitudes and behavioral reactions after the introduction of a measure, whereas acceptability is only an attitude toward a measure, hypothesized before its introduction. A more nuanced differentiation between acceptance and support helps develop this argument. We suggest that both acceptance and support include a positive attitude toward the policy, but only support includes the behavioral dimension of intent or action. In this way, acceptance represents an attitude structure, which is passive; support includes not only this same attitude structure, but also a more active behavioral dimension. 
An example of policy support would be a behavior such as voting where you actively go to the polls to cast your vote on a specific issue. Thus, your positive or negative attitude transcends from a passive idea to an active behavior. If acceptance is more passive, then an individual may not need to behave in any way to accept it. For example, one abstains from voting on that issue, but this person has a high level of acceptance and, if asked, would say he or she finds the policy acceptable. Thus, it is possible, and perhaps even common, for an individual to find a policy acceptable while not actively supporting it. It is also possible for this to work in the opposite direction. An individual may find a policy not acceptable, but not actively oppose the policy. However, when asked if they support the policy they may indicate that they do not.

It may also be possible to further differentiate between acceptance and support on a temporal dimension. Support may be a construct which spans the before implementation/after implementation policy divide whereas acceptance is situated within the after implementation sphere (and acceptability within the before implementation sphere). If a policy is proposed, one may support its future implementation through political action such as calling a representative to indicate their support or gaining signatures on a petition. One may support its immediate implementation through voting. Lastly, one may support its continued existence through a number of actions or intentions to act if the policy was at risk of being overturned.

One explanation for the non-differentiation of these terms can be found in the willingness to pay (WTP) and willingness to accept (WTA) the literature in economics. WTP and WTA have also 
been theorized to be very similar measures; however, in practice they often diverge (Hanemann, 1991; Shogren, Seung, Hayes, \& Kliebenstein, 1994). The active amount an individual would be willing to pay to secure a change of some sort is not necessarily the same amount that they would be willing to accept to passively forego this. Hanemann (1991) notes this divergence is based not only on an income effect of participants, but also the availability of a close substitute. Thus, it should not be assumed that WTP and WTA would produce similar values. In a similar way, we suggest that policy acceptance and policy support should not be assumed to be equivalent, nor even be thought of as the same construct. More studies should follow to test this finding.

One could argue that we found differences in support and acceptance due to measurement issues alone. The question about policy support required a dichotomous response (with no neutral category); the question about policy acceptance offered a scale for responses. Hence, it is possible that the different patterns of responses to the two questions could be attributable to the different response formats. However, for this study it was important to construct the support question as dichotomous, to parallel the political process - a vote in parliament for the legislative package must be either for or against the bill, with no possibility of shading support or opposition by degrees. In that sense then, even if the present differences between support and acceptance can be attributed to response format, it does not undermine the external validity of the result.

A somewhat related issue to this scaling issue arises when we consider the motivations of those who responded 'neutral' to the acceptance question: it is not possible to distinguish those who 
were indifferent from those who were ambivalent. Attitudinal ambivalence can reflect evaluative inconsistency, or a midway point between two opposite views (Costarelli \& Colloca, 2004) and when considering complex environmental issues, an individual may hold ambivalent attitudes (Seidl, Moser, Stauffacher, \& Krütli, 2012). This ambivalence does not necessarily indicate a lack of opinion or indifference. However, once again, this measurement issue reflects the reality of the policy space.

Ambivalence can arise in another sense too. Policies can be evaluated for fairness in both microand macro-terms (Tyler et al., 1997). Clayton (2000) has found that environmental groups are more likely to base their arguments on principles concerning the larger society (macrojustice) while antienvironmental groups focus on the individual (microjustice). In our study, when forced to indicate their support (or otherwise) for a policy, participants' sense of the microlevel (in)justice of redistribution of funds to individuals and households may outweigh their sense of the macro level of (in)justice of holding individual companies responsible for emissions. The tension between the use of micro- and macro-justice principles to evaluate the fairness of policies, which possibly gives rise to ambivalence, has received little or no attention in the literature, but deserves further investigation.

The existence of an interaction between free-market ideology and effectiveness on acceptance was hypothesized; however, we assumed that the interaction would work differently. We proposed that when free-market ideology was high, acceptance would be low, regardless of levels of effectiveness, but when free-market ideology was low, then perceptions of effectiveness 
would have an influence. Instead, we found a different interaction within support, not acceptance. The stronger one's subscription to a free-market ideology is, the less likely one is to support the policy - except when effectiveness is high. When effectiveness is perceived to be high, individuals both low and high in free-marked ideology were equally likely to support the policy. This is an unexpected finding and deserves more consideration through future studies specifically. It would be interesting to examine why and when those who have a high endorsement of free-market ideology find an environmental policy effective. One speculation is that if a regulatory strategy builds upon market forces (for example instituting a carbon price but allowing the market to drive industries towards environmental innovation) then when the policy is deemed effective, an endorsement of free-market ideology may be in-line with policy support. ${ }^{6}$

This research adds to the current environmental policy literature as it assesses a recently implemented policy. The majority of other studies of this sort assess a hypothetical policy and intention to support that policy. This research finds that perceived levels of effectiveness and fairness are important predictors of policy acceptance. The predictors of policy support are less clear, as they depend on the interaction between free-market ideology and effectiveness. This interplay of factors needs further investigation. Furthermore, it would be helpful to measure changes in policy acceptance and support over time, especially if a change in government occurs. $^{7}$ Thus, it would be beneficial to replicate, and add to, this study in due time.

This research highlights the distinction between policy acceptance and policy support. These terms have been used interchangeably in the literature, leading to a lack of specificity within 
extant measures. Future research should attempt to distinguish operationally policy acceptance and policy support for implemented policies. If the present results are replicated, this distinction would then have significant implications for theories of ESB.

In conclusion, these results suggest that if Australian government officials, and other communicators of the dimensions of climate science and policy, were to stress the effectiveness and/or fairness of the current carbon policy, they may encourage more acceptance and support for climate relevant policies. Along these lines, individuals should have access to effectiveness metrics so they can also see for themselves if the policy is measuring up to its intended goals. ${ }^{8}$ It would be productive to consider two types of effectiveness metrics; one indexing changes in emissions; and the other summarizing the allocation of revenues from the carbon price via compensation. The continued merging of the disciplines of economics and psychology from an environmental perspective will help achieve these suggestions. It is our hope that by attempting to answer our research questions, we can begin to more fully understand how Australians perceive the carbon pricing policy. The more we understand how it is perceived, the better lessons we can learn from its implementation as Australia moves toward its current emission reduction goals. 


\section{Acknowledgments}

This research was supported by a research fellowship from the Endeavour Awards for the principal investigator and funds from the Commonwealth Scientific and Industrial Research Organization. We would like to thank Zoe Leviston, Henry Covey, and two anonymous peer reviewers for their helpful feedback.

\section{Ethical Standards}

This research has been assessed against the requirements of the National Statement as posing a low-risk to participants and has been granted ethics clearance in Australia by the Commonwealth Scientific and Industrial Research Organisation.

\section{Conflict of interest}

The authors declare that they have no conflict of interest. 


\section{Appendix 1}

Thank you for participating in our survey. Please answer each statement or question as honestly as you can. There are no right or wrong answers; we are interested in your opinions.

\section{Section 1}

This section asks you to indicate how strongly you agree or disagree with the following statements.

\begin{tabular}{lllll}
1 & 2 & 3 & 4 & 5 \\
$\begin{array}{l}\text { Strongly } \\
\text { Disagree }\end{array}$ & Disagree & Neutral & Agree & $\begin{array}{l}\text { Strongly } \\
\text { Agree }\end{array}$ \\
\hline
\end{tabular}

1 An economic system based on free-markets unrestrained by government interference automatically works best to meet human needs.

2 I support the free-market system, but not at the expense of environmental quality.

3 The free-market system may be efficient for resource allocation, but it is limited in its capacity to promote social justice.

4 The preservation of the free-market system is more important than localized environmental concerns.

5 Free and unregulated markets pose important threats to sustainable development.

6 The free-market system is likely to promote unsustainable consumption.

7 Individual consumers should be financially compensated to offset increased costs on goods resulting from a carbon price.

8 Industries should be responsible for paying for the greenhouse gases that they emit, such as carbon. 


\section{Section 2}

Last July, the Australian government instituted the Clean Energy Legislative Package. The government seeks to hold about 500 big industries responsible for the emissions they release through a carbon price, which will have an indirect effect on the price paid for goods. Therefore, the government has also created a compensation package for households indirectly impacted by the carbon price. Below is a quick summary of the government's plan, as stated by their website, Clean Energy Future. Please read this summary to help you answer the following survey questions.

"The Clean Energy Legislative Package...includes the carbon pricing mechanism and delivers support for jobs and competitiveness and Australian's economic growth, while reducing pollution. Households will be assisted through tax reform and increased payments."

- The overall increase in cost of living for average Australian households due to carbon pricing is expected to be modest ... less than one cent for every dollar spent.

- Average food costs are expected to increase by less than $\$ 1$ per week, the average household electricity bill is expected to increase by $\$ 3.30$ per week, and the average gas bill is expected to increase by $\$ 1.50$ per week.

- Households will not face a carbon price on the fuel they use for transport.

- Around $60 \%$ of taxpayers will receive a tax cut of at least $\$ 300$ and no private citizens will pay more tax.

- All the funds raised from the price on carbon will be used to provide the abovementioned tax cuts and increase benefits to households, build a new clean energy future, and support jobs in highly affected industries

(http://www.cleanenergyfuture.gov.au/clean-energy-future/our-plan/).

The following questions ask you about the current carbon policy, in general. It also asks about specific components of the policy such as carbon pricing and compensation. Please indicate your opinions on the scale.

9. How acceptable do you find the Clean Energy Legislative Package?

\begin{tabular}{|c|c|c|c|c|}
\hline 1 & 2 & 3 & 4 & 5 \\
\hline $\begin{array}{l}\text { Completely } \\
\text { unacceptable }\end{array}$ & $\begin{array}{l}\text { Somewhat } \\
\text { unacceptable }\end{array}$ & $\begin{array}{l}\text { Neither acceptable nor not } \\
\text { acceptable }\end{array}$ & $\begin{array}{l}\text { Somewhat } \\
\text { acceptable }\end{array}$ & $\begin{array}{l}\text { Completely } \\
\text { acceptable }\end{array}$ \\
\hline
\end{tabular}

10. How fair do you think it is that some big industries now must pay for the carbon they emit, as mandated by the carbon pricing policy?

\begin{tabular}{lllll}
\hline 1 & 2 & 3 & 4 & 5 \\
\hline Completely unfair & Somewhat unfair & Neutral & Somewhat fair & Completely fair \\
\hline
\end{tabular}


11. How effective do you think the carbon pricing policy will be to help lower carbon emissions from industries in Australia?

\begin{tabular}{lllll}
\hline 1 & 2 & 3 & 4 & 5 \\
\hline Completely ineffective & Somewhat ineffective & Neutral & Somewhat effective & Completely effective \\
\hline
\end{tabular}

12. How fair do you think the compensation plan is for those affected by increased costs due to the carbon price?

\begin{tabular}{lllll}
\hline 1 & 2 & 3 & 4 & 5 \\
\hline Completely unfair & Somewhat unfair & Neutral & Somewhat fair & Completely fair \\
\hline
\end{tabular}

13. How effective do you think the compensation plan is in reducing the financial impact of the carbon price on individuals?

\begin{tabular}{lllll}
\hline 1 & 2 & 3 & 4 & 5 \\
\hline Completely ineffective & Somewhat ineffective & Neutral & Somewhat effective & Completely effective \\
\hline
\end{tabular}

14. Do you support the carbon policy (The Clean Energy Legislative Package)? Yes

No 


\section{References}

Australian Bureau of Statistics. (2011). Quick Stats [Census Information]. Retrieved from http:/www.abs.gov.au/websitedbs/censushome.nsf/home/quicks tats?opendocument\&nav $\operatorname{pos}=220$.

Bubna-Litic, K., \& Chalifour, N. J. (2012). Are climate change policies fair to vulnerable communities? The impact of British Columbia's carbon tax and Australia's carbon pricing policy on indigenous communities. Dalhousie Law Journal, 35(1), 127.

Casillas, C. E., \& Kammen, D. M. (2012). Quantifying the social equity of carbon mitigation strategies. Climate Policy, 12(6), 690-703. doi:10.1080/14693062.2012.669097.

Clayton, S. (2000). Models of justice in the environmental debate. Journal of Social Issues, $56(3), 459-474$.

Costarelli, S., \& Colloca, P. (2004). The effects of attitudinal ambivalence on pro-environmental behavioural intentions. Journal of Environmental Psychology, 24(3), 279-288. doi:10.1016/j.jenvp.2004.06.001.

De Groot, J., \& Steg, L. (2006). Impact of transport pricing on quality of life, acceptability, and intentions to reduce car use: An exploratory study in five European countries. Journal of Transport Geography, 14(6), 463-470. doi:10.1016/j.jtrangeo.2006.02.011.

Dietz, T., Dan, A., \& Shwom, R. (2007). Support for climate change policy: Social psychological and social structural influences. Rural Sociology, 72(2), 185-214. doi:10.1526/003601107781170026. 
Eriksson, L., Garvill, J., \& Nordlund, A. M. (2008). Acceptability of single and combined transport policy measures: The importance of environmental and policy specific beliefs. Transportation Research Part A: Policy and Practice, 42(8), 1117-1128. doi:10.1016/j.tra.2008.03.006.

Gärling, T., \& Schuitema, G. (2007). Travel demand management targeting reduced private car use: Effectiveness, public acceptability and political feasibility. Journal of Social Issues, 63(1), 139-153.

Gehlert, T., \& Nielsen, O. A. (2007). Triangulation of data sources for analysing car drivers' responses to road pricing in Copenhagen. Paper presented at the European Transport Conference, Noordwijkerhout, Netherlands.

Gross, C. (2007). Community perspectives of wind energy in Australia: The application of a justice and community fairness framework to increase social acceptance. Energy Policy, 35(5), 2727-2736. doi:10.1016/j.enpol.2006.12.013.

Hanemann, M. (1991). Willingness to pay and willingness to accept: How much can they differ? American Economic Review, 81(3), 635-647.

Heath, Y., \& Gifford, R. (2006). Free-market ideology and environmental degradation: The case of belief in global climate change. Environment and Behavior, 38(1), 48-71. doi:10.1177/0013916505277998.

Jaffe, A. B., Newell, R. G., \& Stavins, R. N. (2005). A tale of two market failures: Technology and environmental policy. Ecological Economics, 54, 164-174. doi:10.1016/j.ecolecon.2004.12.027. 
Leiserowitz, A., Maibach, E., Roser-Renouf, C., \& Hmielowski, J. D. (2012). Climate Change in the American Mind: Americans' global warming beliefs and attitudes in March 2012. Yale University and George Mason University. New Haven, CT: Yale Project on Climate Change Communication. http://environment.yale.edu/climate/files/Climate-BeliefsMarch-2012.pdf.

Lewandowsky, S., Oberauer, K., \& Gignac, G. E. (2013). NASA faked the moon landingTherefore, (climate) science is a hoax: An anatomy of the motivated rejection of science. Psychological Science, 24(5), 622-633. doi:10.1177/0956797612457686.

Schade, J., \& Schlag, B. (2003). Acceptability of urban transport pricing strategies. Transportation Research Part F: Traffic Psychology and Behaviour, 6, 45-61. doi:10.1016/S1369-8478(02)00046-3.

Schuitema, G., Steg, L., \& Forward, S. (2010a). Explaining differences in acceptability before and acceptance after the implementation of a congestion charge in Stockholm. Transportation Research Part A: Policy and Practice, 44(2), 99-109. doi:10.1016/j.tra.2009.11.005.

Schuitema, G., Steg, L., \& Rothengatter, J. A. (2010b). The acceptability, personal outcome expectations, and expected effects of transport pricing policies. Journal of Environmental Psychology, 30(4), 587-593. doi:10.1016/j.jenvp.2010.05.002.

Seidl, R., Moser, C., Stauffacher, M., \& Krü tli, P. (2012). Perceived risk and benefit of nuclear waste repositories: Four opinion clusters. Risk Analysis. doi:10.1111/j.15396924.2012.01897.x. 
Shogren, J., Seung, S., Hayes, D., \& Kliebenstein, J. (1994). Resolving differences in willingness to pay and willingness. The American Economic Review, 84(1), 255-270.

Skitka, L. J., Winquist, J., \& Hutchinson, S. (2003). Are outcome fairness and outcome favorability distinguishable psychological constructs? A meta-analytic review. Social Justice Research, 16(4), 309-341.

Smith, A. (1904). Of restraints upon the importation from foreign countries of such goods as can be produced at home, Chapter 2. In E. Cannan (Ed.), An inquiry into the nature and causes of the wealth of nations (Vol. 1). London: Methuen and Co., Ltd.

Steg, L., Dreijerink, L., \& Abrahamse, W. (2005). Factors influencing the acceptability of energy policies: A test of VBN theory. Journal of Environmental Psychology, 25(4), 415-425. doi:10.1016/j.jenvp.2005.08.003.

Steg, L., Dreijerink, L., \& Abrahamse, W. (2006). Why are energy policies acceptable and effective? Environment and Behavior, 38(1), 92-111. doi:10.1177/0013916505278519.

Stern, P. C. (2000). Toward a coherent theory of environmentally significant behavior. Journal of Social Issues, 56(3), 407-424.

Stern, P. C., Dietz, T., Abel, T., Guagnano, G. A., \& Kalof, L. (1999). A value-belief-norm theory of support for social movements: The case of environmentalism. Human Ecology Review, 6(2), 81-97.

Swim, J. K., Clayton, S., Doherty, T., Gifford, R., Howard, G., Reser, J. et al. (2011). Psychology and global climate change: Addressing a multi-faceted phenomenon and set 
of challenges. A Report by the American Psychological Association's Task Force on the Interface between Psychology and Global Climate Change.

Tabachnick, B. G., \& Fidell, L. S. (2007). Using multivariate statistics (5th ed.). Boston: Allyn and Bacon.

Thibaut, J. W., \& Walker, L. (1975). Procedural justice: A psychological analysis. New York: Lawrence Erlbaum Associates Inc.

Tyler, T. R. (2000). Social justice: Outcome and procedure. International Journal of Psychology, 35(2), 117-125. doi:10.1080/002075900399411.

Tyler, T. R., Boekmann, R. J., Smith, H. J., \& Huo, Y. J. (1997). Social justice in diverse society. Boulder, CO: Westview Press.

Visschers, V. H. M., \& Siegrist, M. (2012). Fair play in energy policy decisions: Procedural fairness, outcome fairness and acceptance of the decision to rebuild nuclear power plants. Energy Policy, 46, 292-300. doi:10.1016/j.enpol.2012.03.062.

Wegener, D. T., \& Kelly, J. R. (2008). Social psychological dimensions of bioenergy development and public acceptance. Bioenergy Research, 1, 107-117. doi:10.1007/s12155-008-9012-z.

Wolkinger, B., Steininger, K. W., Damm, A., Schleicher, S., Tuerk, A., Grossman, W., et al. (2012). Implementing Europe's climate targets at the regional level. Climate Policy, 12(6), 667-689. doi:10.1080/14693062.2012.669096. 
Wüstenhagen, R., Wolsink, M., \& Bürer, M. J. (2007). Social acceptance of renewable energy innovation: An introduction to the concept. Energy Policy, 35(5), 2683-2691. doi:10.1016/j.enpol.2006.12.001. 


\section{Footnotes}

${ }^{1}$ It can be argued that studying the acceptance of a policy is more important than acceptability because of the potential consequences of non-acceptance via opposition do not exist for hypothetical policies: breaking the law, civil disobedience, or revolt. We believe, however, that both are important, and studying the acceptance of the carbon policy in Australia was, in part, a result of research timing.

${ }^{2}$ See Bubna-Litic \& Chalifour (2012) for their assessment of the carbon policy on Indigenous populations in Australia.

${ }^{3}$ Results from our initial analysis led us to ask more questions about the differences about policy support and acceptance, therefore, later in this paper we will discuss results based on policy support.

${ }^{4}$ This panel is administered by the Online Research Unit, an online fieldwork company with QSOAP "Gold Standard” and the new Global ISO 26362 standard accreditation.

${ }^{5}$ Equal variances assumed for all $t$ tests.

${ }^{6}$ We thank one of our anonymous reviewers for this interesting speculation.

${ }^{7}$ We note that an Australian federal election is due in September 2013. The current Labour government may lose to a conservative coalition, and the coalition has promised, as an election platform, to repeal the carbon pricing legislation.

${ }^{8}$ We realize that only providing information via these proposed metrics is not an effective way to facilitate behavior change regarding policy support. However, we do believe it is an important part of the overall process. 
Table 1 Comparison of demographics between sample and Australian population (Australian Bureau of Statistics, 2011)

\begin{tabular}{|c|c|c|c|c|c|c|c|}
\hline & \multicolumn{2}{|l|}{ Sex } & \multirow{2}{*}{$\begin{array}{l}\text { Median } \\
\text { age (years) }\end{array}$} & \multicolumn{3}{|c|}{ Level of higher education completed } & \multirow{2}{*}{$\begin{array}{l}\text { Median } \\
\text { income }\end{array}$} \\
\hline & $\begin{array}{l}\text { Male } \\
(\%)\end{array}$ & $\begin{array}{l}\text { Female } \\
(\%)\end{array}$ & & $\begin{array}{l}\text { Trade/ } \\
\text { TAFE }(\%)\end{array}$ & $\begin{array}{l}\text { Undergraduate } \\
(\%)\end{array}$ & $\begin{array}{l}\text { Postgraduate } \\
(\%)\end{array}$ & \\
\hline Australia & 49.4 & 50.6 & $37^{\mathrm{a}}$ & 17.4 & 17.0 & 6.7 & 577/week \\
\hline Sample & 49.5 & 50.5 & 46 & 19.8 & 20.8 & 15.3 & $400-599 /$ week $^{\mathrm{b}}$ \\
\hline
\end{tabular}

a Just over $25 \%$ of the Australian population is between the ages of $0-19$. We only sampled those 18 years and older

${ }^{b}$ We assessed income as a categorical variable; therefore, the median categorical group is represented here 


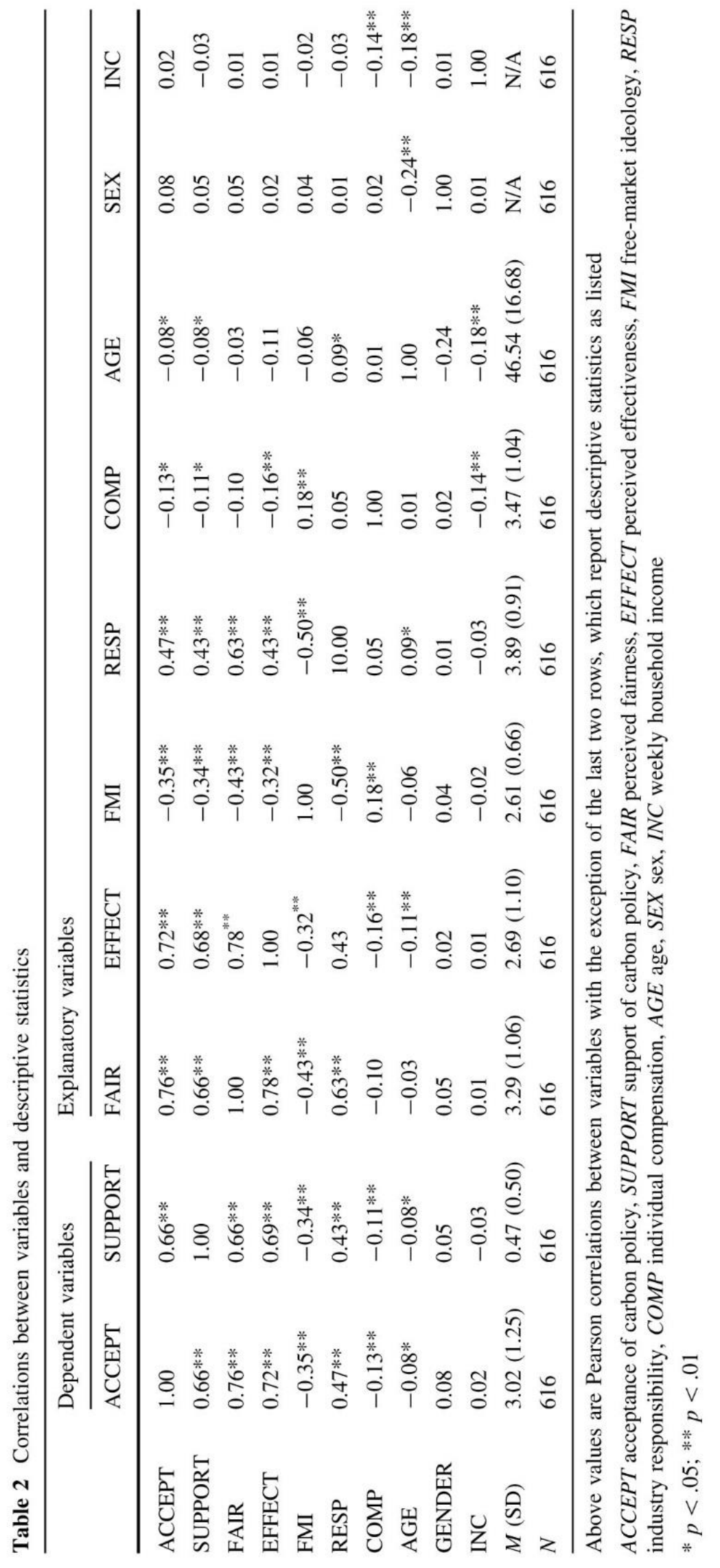


Table 3 Mean values and standard deviations in parentheses for each explanatory variable by level of policy acceptance and support

\begin{tabular}{|c|c|c|c|c|c|c|}
\hline & \multicolumn{5}{|c|}{ Explanatory variable } & \multirow[t]{2}{*}{$N$} \\
\hline & Fairness & Effectiveness & $\begin{array}{l}\text { Free-market } \\
\text { ideology }\end{array}$ & $\begin{array}{l}\text { Personal } \\
\text { compensation }\end{array}$ & $\begin{array}{l}\text { Industry } \\
\text { responsibility }\end{array}$ & \\
\hline \multicolumn{7}{|l|}{ Dependent variable } \\
\hline $\begin{array}{l}\text { Completely } \\
\text { unacceptable }\end{array}$ & $1.90(0.85)$ & $1.39(0.65)$ & $2.98(0.76)$ & $3.63(1.22)$ & $3.08(1.18)$ & 96 \\
\hline $\begin{array}{l}\text { Somewhat } \\
\text { unacceptable }\end{array}$ & $2.77(0.79)$ & $2.05(0.80)$ & $2.72(0.58)$ & $3.68(1.0)$ & $3.81(0.80)$ & 124 \\
\hline $\begin{array}{l}\text { Neither } \\
\text { unacceptable } \\
\text { or acceptable }\end{array}$ & $3.23(0.58)$ & $2.75(0.70)$ & $2.75(0.39)$ & $3.34(.87)$ & $3.62(0.67)$ & 132 \\
\hline $\begin{array}{l}\text { Somewhat } \\
\text { acceptable }\end{array}$ & $3.91(0.64)$ & $3.28(0.83)$ & $2.38(0.62)$ & $3.44(1.02)$ & $4.48(0.66)$ & 199 \\
\hline $\begin{array}{l}\text { Completely } \\
\text { acceptable }\end{array}$ & $4.59(0.45)$ & $3.95(0.70)$ & $2.22(0.74)$ & $3.17(1.05)$ & $4.58(0.53)$ & 65 \\
\hline Do not support & $2.63(0.88)$ & $1.99(0.84)$ & $2.82(0.59)$ & $3.58(1.03)$ & $3.52(0.93)$ & 326 \\
\hline Support & $4.04(0.68)$ & $3.49(0.75)$ & $2.37(0.66)$ & $3.34(1.02)$ & $4.30(0.68)$ & 290 \\
\hline Total & $3.29(1.06)$ & $2.69(1.10)$ & $2.61(0.66)$ & $3.47(1.04)$ & $3.89(0.91)$ & 616 \\
\hline
\end{tabular}




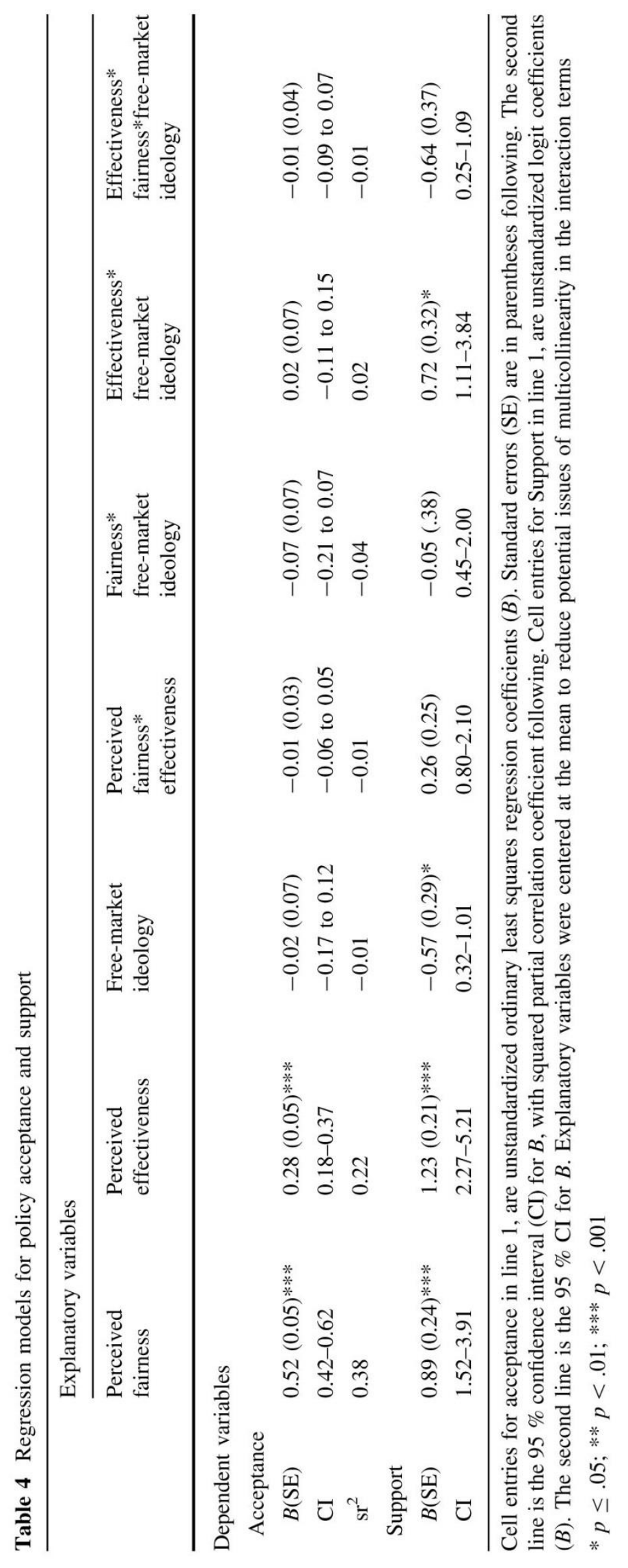

